\title{
CUESTIONES SOBRE EL RÉGIMEN JURÍDICO RECAUDATORIO DE LA SEGURIDAD SOCIAL
}

\author{
EUGENIO RUIZ DE LA CUESTA CARRASCO \\ Profesor Asociado del Departamento \\ de Derecho del Trabajo y Seguridad Social.
}

\begin{abstract}
SUMARIO: I. La nueva normativa: Características y modificaciones introducidas. II. La jurisdicción competente en materia de recaudación: Delimitación del concepto "Actos de gestión recaudatoria". III. La impugnación de los «actos de gestión recaudatoria»: A) Legitimación activa; B) Recursos contra actos de gestión de colaboradores y personal recaudador; C) Recursos contra actos administrativos de gestión recaudatoria: 1. Recurso de Reposición - 2. Reclamación económico-administrativa. 3. La «oposición» a la providencia de apremio.
\end{abstract}

\section{LA NUEVA NORMATIVA RECAUDATORIA: CARACTERÍSTICAS Y MODIFICACIONES INTRODUCIDAS.}

Un estudio del régimen jurídico de la gestión recaudatoria de la Seguridad Social, aún cuando se refiera a algunos de sus aspectos, requiere, siquiera sea con brevedad, una aproximación a la normativa reguladora de la recaudación del Sistema. Constituye la misma, en el momento actual, y como desarrollo de la Ley 40/1980, de 5 de Julio, el acabado producto normativo en que consisten el R. D. 1.517/1991, de 17 de Octubre, y la O.M. de 8 de Abril de 1992. Ciertamente, no obstante la juventud del anterior Reglamento de Recaudación, aprobado por Real Decreto 716/1986, había quedado, en parte, superado por razón de diveresas normas dictadas con posterioridad a la promulgación del mismo y que habían afectado profundamente su contenido. Entre ellas se pueden citar las siguientes:

- La Ley 33/1987, de 23 de Diciembre, de Presupuestos Generales del Estado para 1988 , cuyo art. 26 , por el que se da nueva redacción a los artículos 15 y 17 de la Ley 40/1980, de Inspección y Recaudación de la Seguridad Social, incide en el devengo de los interses, en los aplazamientos de las deudas y en la prelación de los créditos de la Seguridad Social.

-La Ley 37/1988, de 28 de Diciembre, de Presupuestos Generales del Estado para 1989 que, en su disposición adicional $10^{\mathrm{a}}$. establece y desarrolla la colaboración de las personas físicas y Entidades depositarias de bienes embargables en la gestión 
recaudatoria ejecutiva de débitos a la Seguridad Social, mediante la adición de dos nuevos artículos, con los números 14.bis y 14.ter, a la citada Ley 40/1980.

-Ley 7/1989, de 12 de Abril, de Bases de Procedimiento Laboral, en su disposición transitoria.

-Ley 4/1990, de 29 de Junio, de Presupuestos Generales del Estado para 1990 que, en su disposición adicional 9a, 1 , «De la gestión recaudatoria de determinados ingresos de la Seguridad Social», da nueva redación al art. 15 de la Ley 40/80, de Inspección y Recaudación de la Seguridad Social y que, también en la misma disposición adicional 9a , pero en su número 2, introduce el art. 17 bis de dicha Ley, relativo a la transacción y el arbitraje sobre los derechos de la Seguridad Social.

- La anterior Ley Presupuestaria, en cuya disposición adicional 10a , establece un nuevo sistema de recargos y de formas y supuestos de la reclamación administrativa de las deudas con la Seguridad Social respecto de los establecidos en el art. 55 de la Ley 44/1983, de 28 de Diciembre, artículo éste que, además, se deja sin efecto expresamente por la disposición derogatoria $1^{\mathrm{a}}$ de la propia ley Presupuestaria para 1991.

Tal cúmulo de reformas legislativas del sistema recaudatorio, amén de otras de nivel reglamentario, efectuadas en tan breve periodo temporal, hacía necesaria e ineludible la adaptación del contenido del antiguo Reglamento de Recaudación que, más pronto de lo deseable, quedó, siquiera parcialmente, inservible. En efecto, poco después de aprobarse el mismo, el R.D. 1.328/86, de 9 de Mayo, dispuso que el ejercicio de la actividad recaudatoria en el ámbito de la Seguridad Social se llevaría a cabo mediante órganos propios de la Administración de la Seguridad Social y, concretamente, de la Tesorería General de la misma, frente al sistema de conciertos con Organismos ajenos, el cual constituía la base sobre el que se instrumentó el articulado del reglamento General de 1986. Consecuencia de todo esto es la promulgación de las nuevas normas recaudatorias, cuyas modificaciones introducidas, y que después concretaremos, responden, en su conjunto a tres grandes directrices:

a) La primera, específica de la recaudación en periodo voluntario, es la del automatismo o por el mero transcurso del tiempo fijado, tanto para la incidencia en mora como también, en parte, para la expedición de las certificaciones de descubierto.

b) La segunda directriz es la de intensificación de la publificación de la gestión recaudatoria, en cuanto función pública asumida en todo su alcance por órganos u Organismos de la respectiva Administración, en este caso, por la Tesorería General de la Seguridad Social.

c) La tercera directriz es la de la acentuación de la unidad esencial de la recaudación administrativa, sobre todo, en vía ejecutiva.

Nos referiremos a las novedades más importantes que, a nuestro juicio, introduce el nuevo R.D. respecto a la normativa anterior: 
1. Respecto al objeto de la gestión recaudatoria, se delimita el alcance de las competencias recaudatorias de la Tesorería General; así, ella se encarga de la cobranza de los capitales-coste de renta y otras cantidades que deben ingresar las Mutuas de Accidentes de Trabajo y Enfermedades Profesionales y las empresas declaradas responsables de prestaciones, siempre que se haga por una «resolución administrativa». Y, asimismo, que procederá la cobranza por la Tesorería General cuando se trate de prestaciones indebidamente percibidas «declaradas por la Entidad Gestora competente mediante resolución firme de la misma». Se elimina así lo que admitía el anterior Reglamnento, con un claro carácter inconstitucional, de la atribución de la cobranza de débitos reconocidos en sentencia judicial, lo que, obviamente, vulneraba el art. 117.3 de la Constitución española.

2. En materia de prelación de créditos se recogen las innovaciones contenidas en la Ley de Presupuestos Generales del Estado para 1990, dando nueva redacción al art. 15 de la Ley 40/1980, en virtud de la cual los créditos por cuotas de la Seguridad Social y conceptos de recaudación conjunta gozan respecto de la totalidad de los mismos y «sin limitación temporal alguna» de igual prefrencia que los créditos previstos en los arts. 1924, apartado primero, del Código Civil, y 1913, 1,d), del Código de Comercio. La diferencia estriba en que en el anterior Reglamento se establecía una importante limitación temporal al reducir la prelación a las cuotas devengadas en el último año.

3. Se incorpora el contenido de la Ley de Presupuestos para 1990, que modificaba el art. 17bis de la Ley 40/1980, al disponer que no cabe transacción judicial ni extrajudicial sobre los derechos de la S. S. ni el sometimiento a arbitraje de los derechos que se susciten respecto de los mismos, sino mediante Decreto acordado en Consejo de Ministros, previa audiencia del de Estado.

Asimismo, admite la excepción, también contenida en el mismo precepto citado, relativa a la posible suscripción de convenios o acuerdos por parte de la Tesorería General en los procedimientos concursales, incluídos los de quita y espera.

4. Una de las novedades más importantes del nuevo Reglamento se deriva de los cambios producidos por la Disposición Adicional 10 de la Ley 31/90 de Presupuestos para 1991, en orden a periodos de recaudación y recargos. En efecto, con anterioridad a esta nueva regulación se imponía, con carácter general, la necesidad de la previa reclamación administrativa por la Tesorería General de las cuotas adeudadas antes de la expedición por ellas de la correspondiente certificación de descubierto. Tal reclamación se efectuaba mediante dos vías: la notificación de descubierto, para el caso de que la empresa hubiere presentado en la Tesorería General los documentos de cotización, sin abonar las cuotas; y el requerimiento de cuotas, cuando el imcumplimiento del pago de cuotas se produjera sin presentación también de los citados documentos. Pues bien, se suprime la exigencia de la 
notificación de deudas en el caso de haber presentado el deudor los documentos de cotización dentro del plazo reglamentario, es decir, no se reclama por vía administratuiva a la empresa una cantidad que ya ella misma ha declarado y reconocido, lo que suponía un trámite innecesario y dilatorio del procedimiento de recaudación. Por lo tanto, sólo se mantiene la reclamación administrativa de la deuda, a través del requerimiento de cuotas, cuando el responsable del pago de las cuotas no haya liquidado o reconocido el importe de las mismas.

$\mathrm{El}$ régimen de los recargos por mora en deudas por cuotas sigue diversificado según se hayan presentado o no los documentos de cotización dentro del plazo reglamentario de ingreso: así, en el primer supuesto, si las cuotas debidas se pagan dentro de los dos meses naturales siguientes al del vencimiento del plazo reglamentario, el porcentaje de recargo es del $5 \%$ de la deuda; si se ingresan después de los dos meses pero antes de la expedición de la certificación de descubierto, el $20 \%$.

Y en el caso de la no presentación de tales documentos en el plazo reglamentario, el recargo será del $15 \%$ si se abonan las deudas dentro de los dos meses naturales siguientes al del vencimiento del plazo reglamentario de ingreso; y del 20\% si se pagan después de los dos meses pero antes de la expedición de la certificación de descubierto.

Estos recargos por mora son incompatibles entre sí y con el de apremio (20\%) que, asimismo, es incompatible con otro recargo de apremio sobre el mismo débito.

6. La regulación de las certificaciones de descubierto, con independencia de que son objeto de una nueva sistematización, contiene la precisión de que constituyen títulos ejecutivos únicos y suficientes para iniciar la vía de apremio «sin necesidad de ninguna otra exigencia o autorización». En particular, se ha suprimido la preceptiva autorización de las certificaciones por parte de la Dirección Provincial de Trabajo y S.S. como requisito previo para que la Tesorería pudiera dictar la correspondiente providencia de apremio. La competencia territorial de la Tesorería General en los supuestos de estas certificaciones viene determinada por el lugar en el que el empresario tenga autorizada su cuenta de cotización.

7. En fin, otras novedades de menor envergadura, pero que podemos considerar interesantes, podrían se las siguientes:

- Se admite como causa de oposición a la providencia de apremio el error en la declaración presentada en plazo reglamentario, suspendiéndose el mismo hasta su resolución, aunque el interesado haya formulado otras impugnaciones.

-El nombramiento de depositario corresponde, en todo caso, al Recaudador, mientras que, en la anterior regulación, sólo lo realizaba éste último si el deudor no lo hacía.

- Las subastas podrán ser realizadas por empresas especializadas, de acuerdo con sus procedimientos específicos, siempre que se sometan a las siguientes reglas: 
que la tasación y el tipo aplicable sean determinados conforme a lo regulado en el propio Reglamento; que las habilitaciones sean temporales, y que se hagan a través de conciertos autorizados por el Consejo de Ministros.

-En las subastas de bienes muebles, la Tesorería General podrá ejercitar, en 30 días, en todas las licitaciones el derecho de tanteo, inmediatamente después de la adjudicación de los bienes al mejor postor. Hasta ahora, tal derecho procedía sólo en la segunda licitación.

- Igualmente, en la subasta de inmuebles, el Director Provincial de la Tesorería General, podrá ejercitar, durante el plazo de 30 días, el derecho de tanteo, a favor de la Entidad en las dos licitaciones. Antes, tal derecho sólo se admitía en la segunda licitación.

- Se establece que los créditos incobrables respecto de personas o Sociedades inscritas en el Registro Mercantil serán anotados en el mismo, debiendo comunicar éste al órgano de recaudación competente cualquier acto relativo a aquellas que se presente a la inscripción.

-En cuanto a las tercerías, se añade que si el tercerista no aportara con la reclamación los documentos originales en los que se funda su derecho, la Dirección Provincial de la Tesorería ha de requerirle para que, en 10 días, los aporte, archivando la reclamación en caso contrario.

-Por último, en caso de impugnaciones, la garantía a prestar para suspender la reclamación ejecutiva se efectuará mediante aval que cubra el importe de la deuda inicial mas un $20 \%$ de ésta para cubrir el recargo de apremio, intereses, en su caso, y las costas del procedimiento. Antes, el porcentaje era de un $25 \%$, si bien no se aludía a los intereses.

\section{LA JURISDICCIÓN COMPETENTE EN MATERIA DE RECAUDACIÓN: LA DELIMITACIÓN DEL CONCEPTO «ACTOS DE GESTIÓN RECAUDATORIA»}

El art. 3.b) de la vigente Ley de Procedimiento Laboral, de 27 de Abril de 1990 establece que: «No conocerán los órganos jurisdiccionales del orden social:...... b) De las resoluciones dictadas por la Tesorería General de la Seguridad Social en materia de gestión recaudatoria o, en-su caso, por las Entidades gestoras en el supuesto de cuotas de recaudación conjunta». Se delimita así, negativamente, la jurisdicción por razón de la materia del orden jurisdiccional de lo social, cuyo núcleo en materia de Seguridad Social viene determinado en el art. 2.b del mismo texto legal atribuyéndoles el conocimiento de las cuestiones litigiosas que se promuevan................b) En materia de Seguridad Social, incluída la protección por desempleo.

Este art. 3. b) de la vigente Ley Procesal viene a cerrar una amplia y aguda 
polémica, doctrinal y judicial, que se había suscitado en orden a la jurisdicción competente para conocer de las impugnaciones en materia de recaudación. En efecto, la anterior Ley procedimental de 13 de Junio de 1980, amplió, sin fundamento legal suficiente para ello, el art. 19 de la Ley General de la Seguridad Social, al establecer en su art. I-6 que son competentes los órganos judiciales de lo social para, conocer, además de los pleitos de Seguridad Social de las «ejecuciones en vía de apremio derivadas del incumplimiento de las obligaciones respecto a la Seguridad Social» (mientras que el art. 19 de la Ley General de Seguridad Social habla únicamente del «incumplimiento de la obligación de cotizar»), y al añadirse en el art. 127 una nueva causa de oposición al apremio consistente en la «ilegalidad de la exacción o su cuantía», estableciendo el art. 131 la posibilidad de enjuiciar la legalidad de la exacción y de su cuantía, con independencia de la validez del título constituído por la Certificación de descubierto, es evidente que esta Ley Procesal amplió netamente la competencia de las Magistraturas de Trabajo, disminuyendo la fuerza ejecutiva de los títulos ejecutivos expedidos por la propia S.S. frente a los deudores, al poder alegarse por éstos, como motivo de oposición, la ilegalidad de la exacción en sí o la improcedencia de su cuantía.

Pero, paralelamente y frente a ésto, la Ley 40/1980, de 5 de Julio, de Inspección y Recaudación de la Seguridad Social, refuerza la ejecutividad de los títulos administrativos, al disponer en su art. II-I que «serán títulos ejecutivos suficientes para iniciar la vía de apremio las certificaciones de descubierto acreditativas del débito a la Seguridad Social, que tendrán la misma fuerza ejecutiva que las sentencias judiciales». A su vez, esta misma norma consagra el retorno de la función recaudatoria ejecutiva a la Tesorería General de la Seguridad Social, sin perjuicio de la subsistencia del concierto recaudatorio con las propias Magistraturas de Trabajo.

Hay que resaltar de este proceso algo esencial: la caracterización de las potestades de recaudación en vía ejecutiva en potestades típicamente administrativas.

De lo expuesto resalta la evidente disparidad entre la Ley de Procedimiento Laboral y la Ley de Inspección y Recaudación, lo que planteó el problema de qué ley debía prevalecer, sobre todo si se tiene en cuenta que la Ley Procesal, de 13 de Junio, fue publicada con posterioridad (el 30 de Julio) a la de Inspección y Recaudación, de 5 de Julio (el 24 de Julio). Pasando por alto la polémica doctrinal desatada al respecto, simplemente señalaremos que prevaleció la tesis que defendía que. la Ley de Inspección y Recaudación deroga, en este punto, a la Ley de Procedimiento Laboral.

Así las cosas, se aprueba el RD. 716/1986, de 7 de Marzo que establece el Reglamento General de Recaudación de los Recursos del Sistema de la Seguridad Social, desarrollado por la O.M. de 23 de Octubre de 1986. Ambas normas explicitan con generosidad el mandato de la Ley 40/80 y del Real Decreto-Ley 10/1981, 
normas que encomiendan a la Tesorería General de la Seguridad Social, por su carácter de Caja única del sistema de la Seguridad Social, la gestión recaudatoria tanto en periodo voluntario como en vía ejecutiva, bajo la dirección y tutela del Estado. En efecto tras definir el art. 1 del R.D. que se entiende por gestión recuadatoria en el ámbito de la Seguridad Social «el ejercicio de la actividad administrativa conducente a la realización de los créditos y derechos que formen parte del patrimonio de la Seguridad Social respecto de aquellos recursos de la misma que se especifican en el presente R.D.», proclama su art. $2^{\circ}$, respecto a la competencia material:

La gestión recaudatoria de las cuotas y demás recursos de financiación del sistema de la Seguridad Social... es de competencia exclusiva de la Tesorería General de la Seguridad Social, que la ejercerá bajo la dirección, vigilancia y tutela del Ministerio de Trabajo y Seguridad Social, y con sujeción a las normas contenidas en la Ley General de la Seguridad Social... Ley de Inspección y Recaudación.

Desaparece, pues, todo asomo de atribución de competencias a las Magistraturas de Trabajo, que únicamente continuarán conociendo de los procedimientos de apremio ya iniciados en la fecha de entrada en vigor del Reglamento de Recaudación, de acuerdo con lo dispuesto en las Disposiciones Transitorias $2^{\underline{a}}$ y $4^{a}$ del mismo.

Si desde el plano normativo parece que la cuestión había quedado aclarada en el sentido de que la jurisdicción contencioso-administrativa era la competetente para conocer de las impugnaciones contra los actos de gestión recaudatoria, sin embargo se producen algunas Resoluciones en sede de los Tribunales Económico-Administrativos, vía previa que ha de agotarse para acudir a dicha jurisdicción, que, inicialmente al menos, sembraron nueva confusión en la materia.

Una de las más prematuras fue la Resolución del Tribunal Económico-Administrativo Central de 3 de Febrero de 1987, conociendo de la impuganción de una liquidación efectuada por la Tesorería General en concepto de prima única. Dicha liquidación contenía una intimación al pago y señalaba que contra la misma, y de conformidad con el Reglamento de Recaudación (art. 188), podría interponerse reclamación económico-administrativa. La Resolución parte de la definición que de la «gestión recaudatoria» da el art. $1^{\circ}$ del citado Reglamento, el que considera como tal «la actividad administrativa conducente a la realización de los créditos y derechos que formen parte del patrimonio de la Seguridad Social respecto de aquellos recursos que se especifican...» en el art. 4, que define el objeto de la gestión recaudatoria como la cobranza de los recursos de la misma que detalla, la cobranza de las cuotas que menciona y la actividad dirigida a la obtención de las aportaciones que reseña. Sobre esta base, el Tribunal deduce que exclusivamente los actos de recaudación, en sentido estricto, esto es, los de apremio son de sus competencia, excluyendo de la misma a la actividad administrativa previa de reclamación (esto es, los requerimientos de cuotas y las notificaciones de descubierto). 
La tesis de esta Resolución es harto criticable: $1^{\circ}$ - Disocia los actos de apremio de los administrativos previos cuyo objeto, sustancialmente, consiste en la concreción de la cantidad reclamable, concreción que tiene un doble fundamento: cuantificar la realidad de la deuda, ya que la cotización empresarial en una «autoliquidación» y como tal puede o no haberse practicado o realizado defectuosamente; y posibilitar al sujeto pasivo la impugnación en fase previa a la de apremio, en caso de error administrativo. $2^{\underline{\alpha}}$.- Tiene el desacierto que provoca la ruptura en el enjuiciamiento de un mismo tema dividéndolo en dos partes: lo liquidatorio se enjuiciaría en la jurisdicción laboral, y lo recaudatorio en la jurisdicción contencioso-administrativa.

El Tribunal Supremo, sin embargo, poco tiempo después, establece una doctrina que se consolida inmediatamente y que revoca o contradice a la antes expuesta. La sentencia de 21 de Septiembre de 1987 desestima un recurso de casación por infracción de Ley interpuesto contra una sentencia de Magistratura que se declara incompetente para conocer la impugnación de una notificación de descubierto. El recurso se interpuso ante la jurisdicción laboral en razón de ser ésta la vía que indicó expresamente la entidad gestora.

La tesis fundamental expuesta en esta sentencia se resume en el Fundamente de Derecho segundo, de la misma, que afirma: «El control jurisdiccional de la específica gestión recaudatoria de la Seguridad Social está, en principio, atruibuída al orden contencioso-administrativo, como consecuencia de que la misma requerirá normalmente la intervención de órganos de la Administración Central.» A esta conclusión llega el Alto Tribunal de un modo sencillo y totalmente lógico: la descentralizción de la función recuadatoria en la Tesorería General como Organo de la Administración del Estado implica que la actividad de la misma haya de calificarse como actividad administrativa, y los actos emanados de ella en el desarrollo de dicha función constituyen auténticos actos administrativos. Por lo tanto, de conformidad con el art. 9.4. de la Ley Orgánica del Poder Judicial y $1^{\circ} .1$ y 2 de la Ley de Jurisdicción Contencioso-Administrativa, tal será la jurisdicción competente para conocer de los actos administrativos de la gestión recaudatoria.

Pues bien, resuelta ya la cuestión competencial de una forma definitiva en el plano legislativo por el arriba citado art. 3. b) de la vigente Ley de Procedimiento Laboral, nos quedaría, para completar lo hasta aquí expuesto el tratar una cuestión: ¿en qué consiste la «materia» de Seguridad Social competencia de la jurisdicción laboral, según el art. $2^{\circ}$. b) de la Ley Rituaria? Obviamente en todas aquellas cuestiones que no sean de estricta «gestión recaudatoria» y que, muy escuetamente, podemos enumerar como las siguientes: a) la determinación de los sujetos incluidos en el campo de aplicación de la Seguridad Social, esto es, lo relativo a los denominados «actos de encuadramiento» (afiliación, altas y bajas); b) los requisitos para tener derecho a las prestaciones (determinación de la contingencia protegida y del hecho causante de la prestación); d) la fijación de las prestaciones y su revisión, esto es, cálculo de la prestación, duración y vicisitudes de las mismas, tales como 
suspensión o extinción, reintegro de las prestaciones indebidas... entre otras cuestiones; y d) las diversas responsabilidades en relación a las prestaciones, ya sea por la integridad de ellas, ya se trate de supuestos de recargo de las mismas. Todas ellas son materia de Seguridad Social y están encomendadas, por lo tanto, al conocimiento de la jurisdicción social.

\section{LA IMPUGNACIÓN DE LOS «ACTOS DE GESTIÓN RECAUDATORIA»}

Ponen de relieve García de Enterría y Tomás - Ramón Fernández la doble caracterización que los recursos administrativos tienen en nuestro Ordenamiento Jurídico: son garantía para el administrado y, además, presupuesto de la impugnación jurisdiccional.

En efecto, los recursos administrativos son garantía para el administrado por cuanto éste mediante ellos pide a la propia Administración la revocación o reforma de un acto suyo, posibilitando que la misma reaccione contra dicho acto y pueda, eventualmente, eliminar el perjuicio que comporta. Ahora bien, no debemos olvidar que, dada la estructura y configuración técnica de los recursos, esa garantía tiene un alcance limitado. En efecto, los recursos se interponen ante y se resuelven por la Administración, que reune por ello en este caso la doble condición de juez y parte, y si bien es cierto que la resolución de los recursos se realiza a través de unos trámites formales que, de cierto modo los «procesaliza», siempre faltará un elemento decisivo a la hora de definir y configurar una jurisdicción verdadera y propia: la neutralidad e independencia del órgano llamado a decidir la controversia.

El recurso administrativo se caracteriza, también y a su vez, como una carga para el administrado por cuanto se convierte en presupuesto de la acción jurisdiccional, es decir, que es preciso agotar la vía administrativa con carácter previo a la interposición del recurso contencioso-administrativo que, de otro modo, resulta indamisible. El cumplimiento de esta carga de recurrir previamente en la vía administrativa, dentro, además, de plazos breves, del que dependen tan importantes efectos, implica un importante aplazamiento de la posibilidad de obtener una decisión en Justicia a través de un verdadero proceso y ante una instancia neutral e independiente, lo cual es especialmente grave si se tiene en cuenta que los actos administrativos comienzan a producir efectos desde la fecha en que se dictan, sin que el recurso sirva para frenar o paralizar esa inmediata eficacia, que sólo excepcionalmente, puede ser suspendida. La desorbitada duración que en algunos casos alcanza la vía gubernativa previa (varios años la reclamación económico-adminis-trativa) hace especialmetne dramática esta situación, que parece concebida más en beneficio de la Administraciópn que en garantía de los administrados.

El Reglamento General de Recaudación, de 11 de Octubre de 1991, en su Título 
IV, arts. 185 a 193 regula la impugnación de los actos de gestión recaudatoria, siendo desarrollados estos preceptos en los arts. 186 a 191 de la O.M. de 8 de Abril de 1992. Antes de entrar en el estudio concreto de cada recurso que estas normas recogen, podríamos sintetizar como características esenciales del régimen impugnatorio, las siguientes:

a) Objeto de impugnación son la totalidad de los actos de gestión recaudatoria, en el sentido antes examinado, es decir, tanto los actos administrativos producidos en la recaudación en periodo voluntario, como, lógicamente, los actos producidos en fase ejecutiva o de apremio.

b) Se excluyen de la posibilidad de impugnación por esta normativa las Actas de Liquidación emitidas o formuladas por la Inspección de Trabajo, que proceden para la liquidación de cuotas por falta de afiliación o de alta, así como las debidas por diferencias de cotización respecto a trabajadores que figuren dados de alta, las cuales se sujetan al régimen impugnatorio de sus normas especiales.

c) Es objeto de regulación separada en el Reglamento la llamada «oposición al apremio», esto es, la específica impugnación de la Certificación de Descubierto, que es el título que abre la vía ejecutiva, y cuya especialidad consiste en que el recurso únicamente puede fundamentarse en motivos tasados.

d) También se excluyen del régimen jurídico impugnatorio de los actos de gestión las llamadas «reclamaciones» que, con carácter previo han de formular los administrados para acudir a la vía jurisdiccional civil, y que se refieren a la interposición de Tercerías de dominio y de mejor derecho que puedan suscitarse como consecuencia o con ocasión del proceso recaudatorio.

Concretando ya los recursos que establece la norma, la misma parte de dos tipos de actos:

- Los de gestión reacudatoria emanados de los colaboradores de la Recaudación, así como los llevados a cabo por el propio Recaudador.

- Los actos administrativos de gestión recaudatoria emanados de las Direcciones Provinciales de la Tesorería General de la Seguridad Social.

A) Legitimación activa. Para impugnar los dos tipos de actos citados, la ostentan:

1. Los obligados al pago de la deuda, así como los responsables solidarios o subsidiarios, y los sucesores «mortis causa» de todos ellos, salvo que lo sean a beneficio de inventario.

2. Cualquier otra personas cuyos intereses legítimos y personales resulten afectados por el acto impugnado (art. 186).

La expresión «intereses legítimos y personales» ha de interpretarse conforme a 
la doctrina y jurisprudencia administrativas en relación con la legitimación para interponer recursos administrativos. Nuestro Tribunal Constitucional, analizando el art. 24 de la Constitución referido al derecho fundamental a la tutela judicial efctiva, ha dicho que la expresión «interés legítimo» ha de entenderse referida a un interés en sentido propio, cualificado o específico, y hace referencia a la idea de un interés protegido por el Derecho, en contraposición a otros que no son objeto de tal protección (STC 257/88). Es decir, ha de ser un interés que derive de una norma jurídica; ha de tratarse de una posición de ventaja o beneficio que provenga del Ordenamiento jurídico. Por tanto, no es admisible el simple interés, o un interés económico o moral. No es necesario que exista un derecho subjetivo, pero sí que la posición que se trate de defender venga amparada por la norma. En definitiva, este precepto otorga legitimación a los que ostenten un interés personal, esto es, referido a una persona o grupo de personas diferenciadas, no un interés genérico o indeterminado; por otro, el interés ha de ser jurídico.

\section{B) Recursos contra actos de gestión de colaboradores y personal recaudador.}

Viene regulado en el art. 187 del Reglamento General. Son colaboradores de la gestión recaudatoria las Entidades Financieras, las Oficinas de Correos y otros Organismos o Agentes autorizados por el Ministerio de Trabajo y Seguridad Social para actuar como oficinas recaudadoras (art. 7.1). Tratándose, efectivamente, la cotización de una autoliquidación que efectúa el empresario o sujeto obligado, el pago de la cuota ha de efectuarse, necesariamente, en periodo voluntario, o mediante autorización por parte de la Tesorería General, en fase de reclamación administrativa, mediante una de estas entidades colaboradoras. Lógicamente, pueden surgir diversas incidencias entre ellas y los obligados al pago de la cotización: desde la negativa a recibir el impreso, hasta haberse efectuado sin que el mismo se haya hecho constar en la Entidad etc...

Por otra parte, para la recaudación de determinadas cuotas las funciones recaudatorias no las asume directamente la Tesorería General, sino que, por tradición, y en virtud de concierto, efectúan dicha recaudación otras Administraciones tributarias (p. ej. las cuotas del Régimen Especial Agrario). De ahí, que el propio art. 7.2 extienda el concepto de colaborador a este tipo de Administraciones e, hipotéticamente, a entidades particulares que pudieran habilitarse en el futuro.

El Recaudador lleva a cabo los actos materiales precisos para la ejecución patrimonial del deudor. Dictada la Providencia de apremio por el Director Provincial de la Tesorería, al Recaudador le corresponde: la práctica de los embargos, el nombramiento de depositario, la designación de peritos en la enajenación de bienes muebles etc...

Tanto respecto a las posibles actuaciones de los colaboradores como del 
recaudador, se desprende algo evidente: no estamos en presencia de actos administrativos, en sentido técnico, sino de meros actos de gestión que, en ciertos casos, pueden causar perjuicio al interesado. De ahí, que la solución legislativa sea consecuente a ésto: dichos actos podrán impugnarse ante la Dirección Provincial de la Tesorería General, dentro del plazo de 8 días siguientes a la notificación del acto que se pretende impugnar, acompañando al escrito la prueba documental pertinente (art. 187.1). El Director Provincial resuelve en un plazo máximo de 15 días (art. 187.2), abriendo esta resolución la vía del recurso administrativo.

Estamos, pues, ante un recurso específico cuya finalidad consiste en la emisión del acto administrativo formal que podrá ser impugnado, independientemente de conceder al Director Provincial la posibilidad de rectificar los errores o reponer el derecho vulnerado por los actos realizados por los órganos y entidades antes mencionados. Producido el acto administrativo, el mismo se puede impugnar mediante los recursos que trataremos a continuación.

\section{C) Reursos contra actos administrativos de gestión recaudatoria.}

El art. 188 del Reglamento nos dice que «contra los actos administrativos de gestión recaudatoria emanados de las Direcciones Provinciales de la Tesorería General............... podrá interponerse reclamación económico-administrativa, de acuerdo con el Reglamento de procedimiento en la materia, sin perjuicio del previo y potestativo recurso de reposición».

El precepto, por lo tanto, determina el acto administrativo impugnable por el Organo de que emana y establece los recursos procedentes contra tales actos.

Hemos visto antes cuáles son y en qué consisten los meros actos de gestión dictados o realizados por los colaboradores de la gestión recaudatoria y por el personal recaudador. Los actos administrativos a que ahora nos referimos, en cuanto emana directamente de la Dirección Provincial, los podemos relacionar en base a la actuación de dicho órgano en el proceso recaudatorio y a la vista del Reglamento. Sin ánimo de agotar la enumeración de los mismos, podemos citar como más importantes, los siguientes: las resoluciones dictadas por la Dirección Provincial en los recursos específicos contra los actos de gestión recaudatoria a que antes nos hemos referido; los requerimientos de cuotas emitidos en el periodo de recaudación voluntaria para proceder a la reclamación administrativa de la deuda; la aprobación y adjudicación de la enajenación de bienes muebles por concurso; la autorización de la subasta de bienes inmuebles; la autorización de la venta por gestión directa de los bienes muebles; igualmente, la enajenación de inmuebles, tanto la autorización de la subasta como la propia adjudicación en subasta y a través de la Mesa presidida por el Director Provincial; el ejercicio del derecho de tanteo a favor de la Tesorería General, así como la reserva de adjudicación a favor del Organismo por el importe 
de la deuda, ambos referidos a la enajenación de inmuebles; las declaraciones de créditos incobrables; las resoluciones declaratorias de la responsabilidad solidaria o subsidiaria de las empresas, etc....

Contra cualesquiera de los mencionados actos administrativos el Reglamento establece la posibilidad de recurrir en vía económico-administrativa, sin perjuicio del previo y potestativo recurso de reposición. A ellos, nos referimos a continuación.

1.- Recurso de Reposición. El art. 189 se refiere a él diciendo que: «El recurso de reposición se interpondrá ante el mismo órgano que dictó el acto, siendo de aplicación lo establecido en las normas reglamentarias que regulen su aplicación». Estas normas reglamentarias a que se refiere el precepto son, obviamente, además del propio Reglamento de recaudación, el de Procedimiento en las Reclamaciones Económico-administrativas, aprobado por R.D. 1.999/1981, de 20 de Agosto, al cual se refier en el art. 1.2. y, muy especial y directamente, el Decreto 2.224/1979, de 7 de Septiembre, que regula ampliamente este recurso previo al económicoadmnistrativo, contra los «actos de la Administración general o institucional del Estado» (art. 1). Veamos, muy brevemente, el régimen jurídico de este recurso:

- La reposición previa al económico-administrativo participa de las notas comunes del recurso de reposición administrativo. Es el recurso administrativo, cuya decisión corresponde al mismo órgano de que proviene el acto objeto de impugnación. Como dice una STS de 30 de Enero de 1958, «el recurso de reposición es aquél que se interpone ante la propia autoridad que ha dictado un acto o pronunciado una decisión administrativa, a fin de someter determinadas consideraciones a la indicada autoridad para que ésta, por acto de contrario imperio, revoque el acto o decisión recurrida».

Las notas características de este recurso de reposición son fundamentalmente, las siguientes: a) que es previo de otros recursos administrativos, concretamente de las reclamaciones económico-administrativas; y b) que siempre tiene carácter potestativo. A diferencia del recurso de reposición previo al contencioso administrativo, que en principio tiene carácter de presupuesto.

-En cuanto al plazo para interponerlo, el art. 4 del Decreto 2.244/79, dice que «el recurso de reposición se interpondrá dentro del plazo de quince días contados desde el siguiente a la notificación del acto cuya revisión se solicita».

-Se interpondrá por medio de escrito (art. 8 D. 2.244), en el que habrá de expresarse: a) que no se ha impugnado el mismo acto en la vía económicoadministrativa y b) en el que se formularán las alegaciones tanto de hecho como de derecho. Lógicamente, y como ya queda dicho, el escrito se dirigirá al mismo órgano que dictó el acto, esto es, al Director Provincial de la Tesorería General de la Seguridad Social. 
-Por lo que respecta a la terminación del procedimiento de recurso, lo hará normalmente con la resolución expresa escrita del órgano ante el que se interpuso, que deberá ser motivada, decidiendo las cuestiones planteadas. La resolución deberá dictarse en el plazo de 8 días. Transcurrido el plazo de un mes desde la presentación del recurso sin que se haya resuelto el mismo se entiende denegado por silencio administrativo.

-Por último, en cuanto a los efectos de la interposición del recurso, el más importante es que interrumpe los plazos para el ejercicio de la reclamación económico-administrativa, que volverán a contarse inicialmente a partir de la fecha en que se hubiere practicado la notificación expresa de la resolución recaída, o, en su caso, del día en que se entienda presuntamente desestimado.

\section{2.- Reclamación económico-administrativa.}

Hemos visto como el art. 188 del Reglamento General se remite, en cuanto a este recurso, a su específico Reglamento de procedimineto. El vigente es el aprobado por R.D. 1.999/1981, de 20 de Agosto, habiendo sufrido una muy importante modificación por R.D. 1.524/1988, de 16 de Diciembre, consistente en una profunda reorganización y atribución de competencias de los Tribunales Económico-Administrativos y que, por lo que a los actos de gestión recaudatoria de la Seguridad Social se refiere, afecta muy directamente, ya que se recoge en la misma expresamente la competencia de dichos órganos para conocer de aquellos.

Desde luego, no vamos a estudiar en este trabajo el procedimiento económicoadministrativo, lo que excedería en mucho al objeto del mismo. Nos referiremos, pues, a las características generales del recurso y a aquéllos de sus trámites más relevantes a los efectos de la gestión recaudatoria de cuotas.

a) Características generales.- El recurso económico-administrativo, además de participar de las notas o caracteres comunes de cualquier recurso administrativo, y a las que antes hemos hecho referencia, se define por una nota característica, que lo diferencia de los demás y que consiste en el peculiar fundamento del mismo. Aún cuando por razones contingentes se haya extendido el ámbito del recurso a otras materias (la más reciente, la propia de Seguridad Social), lo verdaderamente característico del mismo es que la materia sobre la que versa es la jurídico-tributaria. Fueron justamente las peculiaridades de este sector del Ordenamiento jurídico las que postularon unos órganos especializados. El principio de separación de los órganos de gestión y los de resolución postulan por una organización especializada para conocer y decidir las reclamaciones económico-administrativas.

Se ha discutido sobre la naturaleza de éste recurso, de si estamos ante una 
auténtica impugnación jurisdiccional y si los Tribunales Económico-Administrativos son órganos jurisdiccionales. Obviamente, a partir de la Constitución de 1978 tal discusión carece de sentido, pues basta examinar los preceptos que la misma dedica a la jurisdicción y a los órganos jurisdiccionales para llegar a la conclusión de que es absolutamente incontestable la naturaleza estrictamente administrativa de estos Tribunales y de las reclamaciones y recursos que resuelven. Baste señalar al respecto:

-No existe una auténtica independencia organizatoria. Según el art. $8,1, c)$ del Reglamente del procedimiento, el Ministerio de Hacienda resolverá aquellas reclamaciones que «por su índole, cuantía y transcendencia de la resolución que haya de dictarse, considere el Tribunal E.-A. central que deben ser resueltas por el Ministro». Es claro que la norma similar es inconcebible en una actuación jurisdiccional.

-Los miembros del Tribunal Central y de los Tribunales Regionales no gozan de auténtica independencia personal, ya que aquéllos son nombrados y separados libremente por Decreto, previa deliberación del Gobierno (art. 12 RPEA), y éstos por simple Orden del Ministerio de Hacienda (art. 16. 2 RPEA).

-Cuando la reclamación se dirige contra un acto de la Administración del Estado no se da la posición que las partes adoptan en un proceso, sino un recurrente y un órgano que decide. Es decir, un mismo órgano del Estado es juez y representante de una parte, y a su vez titular del interés de una parte.

-En fin, los TEA no ejercen función jurisdiccional, ya que nunca sus resoluciones producen los efectos de la cosa juzgada. La «cosa juzgada administrativa» a que se refiere el art. 61 del RPEA, no es otra cosa que la mera firmeza de la resolución económico-administrativa, y, en todo caso, sus resoluciones definitvas son susceptibles de impugnación ante los órganos de la jurisdicción contenciosoadministrativa (art. 4.2. RPEA).

b) Organización y competencias.-El R.D. 1.524/88 supone una modificación importante en materia de organización y competencias de los TEA. Por una parte, se suprimen los TEA de ámbito provincial, que se sustituyen por únicos Tribunales de ámbito regional o de Comunidad Autónoma que asumen las competencias de aquéllos. Por otro lado, aparece ya explicitada la competencia de los TEA para conocer de los actos de gestión recaudatoria de la Seguridad Social. Respecto a estos últimos, los TEA regionales conocen en primera o única instancia, según la cuantía exceda o no de 3.000 .000 ptas., de las reclamaciones económico-administrativas que se interpongan contra los actos dictados por............. a) Los órganos periféricos............. de la Tesorería Genral de la Seguridad Social (art. 10.1. RPEA); el TEA Central conoce en única instancia de las reclamaciones que se interpongan contra los órganos centrales..... de la Tesorería General de la Seguridad Social, y en segunda instancia de los recursos de alzada que se interpongan 
contra las resoluciones de los TEA Regionales (art. 9 RPEA). Lógicamente, y completando la reforma en lo que aquí nos interesa, se legitima a la Tesorería General tanto para recurrir en alzada ordinaria como para interponer el recurso extraordinario de alzada para la unificación de criterio en los casos no susceptibles de alzada ordinaria (arts. 130 y 131 RPEA).

c) Tiempo y forma del recurso.- El recurso deberá presentarse en el plazo de 15 días hábiles contados a partir del día siguiente a la notificación del acto impugnado. Transcurrido este plazo sin impugnar el acto deviene firme (art. 92 RPEA).

Si se hubiere interpuesto recurso de reposición potestativo, el interesado podrá considerar desestimada su petición al transcurrir un mes desde su interposición, y se computará el plazo a partir del día siguiente. Si optase por esperar a la resolución expresa del recurso de reposición, a partir del día siguiente a la notificación (art. 92 RPEA, y en este último sentido, la Sentencia de 23 de Marzo de 1981, sentando la doctrina de que el silencio administrativo sólo supone una posibilidad de que el interesado formule el recurso admisible, pudiendo esperar a que se dicte el acuerdo expreso).

El procedimiento económico-administrativo, como los demás procedimientos de recurso, se inicia mediante el escrito del recurrente interponiendo el recurso. Ahora bien, así como en los demás procedimientos administrativos de recurso el escrito de interposición debe contener los motivos y razones en que se funde la impuganción, el económico-administrativo puede iniciarse (art. 92.1, RPEA):

1. Mediante el escrito en que el interesado se limite a pedir que se tenga por interpuesta la reclamación. Constituye el supuesto general, ya que los interesados no formulan las alegaciones que fundamentan el recurso hasta que se les ponga de manifiesto el expediente, a fin de conocer los datos de hecho y fundamentos de Derecho que sirvieron de fundamento al acto impugnado. Como dice la Sentencia de 17 de Marzo de 1981, el RPEA «permite, en primer lugar, que la reclamación se inicie mediante el escrito en el que el interesado se limita a pedir que se tenga por interpuesta, reservándose para el trámite previsto en el art. 95 la presentación del escrito con sus alegaciones y con la aportación o proposición de pruebas oportunas».

2. Formulando, además, las alegaciones que crean conveniente a su derecho, con aportación de la prueba pertinente, es decir, interponiendo formalmente el recurso, con el contenido que, para los supuestos generales, regula el art. 114 de la Ley de Procedimiento Administrativo. 


\section{La «oposición» a la providencia de apremio.}

La providencia de apremio es el acto administrativo por el cual se inician las actuaciones de ejecución forzosa sobre el patrimonio del deudor, dirigidas a la satisfacción del crédito. En efecto, el art. 103 del Reglamento establece que «expredida la certificación de descubierto, la Dirección Provincial de la Tesorería General de la Seguridad Social que la hubiere expedido dictará la providencia de apremio, en la que se ordenará la ejecución forzosa sobre bienes y derechos del deudor en virtud de dicha certificación». Como se deduce del precepto, la providencia de apremio es consecutiva al título de ejecución y requisito esencial de la apertura del procedimiento de apremio, hasta el punto que su omisión determina la improcedencia de dicho procedimiento (art. 103.1).

Como quiera que al sujeto pasivo, con anterioridad a la providencia de apremio, le ha sido reclamada la deuda por vía administrativa (a través del requerimiento de cuotas), o bien, la determinación de la misma ha sido efectuada por él directamente (caso de la presentación de los boletines de cotización, con impago de la cuota patronal) y, por lo tanto, en ambos casos, sobre todo en el primero, ha podido frente a dicha reclamación efectuar la impugnación procedente, parece lógico que en la oposición o impugnación de la providencia de apremio le esté vedado la posibilidad de rehabilitar pretensiones impugnatorias que pudieron ser aducidas contra la reclamación administrativa. Por ello, la peculiaridad o característica de esta «oposición» o impugnación específica consiste en que los motivos de impugnación son tasados, en el sentido de que, lógicamente, no podrá efectuar alegaciones sobre las causas o cuantía de la deuda. El art. 103.2 del Reglamento sólo admite como causas de oposición: a) Pago; b) Prescripción; c) Aplazamiento o fraccionamiento de la deuda, concedida con anterioridad a la expedición del título ejecutivo; d) Falta de notificación de la liquidación, cuando ésta sea procedente; e) Defecto formal en la certificación de descubierto o en la providencia de apremio, que les afecte sustancialmente; y, f) Error en la certificación de descubierto, cuando el propio deudor haya presentado en tiempo y forma los boletines de cotización, impagando la cuota patronal.

Como vemos, los motivos de oposición que permite la norma se refieren, bien al presupuesto material de la vía de apremio (por no implicar el incumplimiento del deudor) o a los defectos del título ejecutivo o de la misma providencia de apremio.

Por último, decir que esta impugnación específica sólo será admisible si se presenta o formula dentro de los quince días siguientes al de la notificación de la providencia de apremio, y que su interposición produce la suspensión de procedimiento de apremio hasta la resolución de la misma por la Dirección Provincial de la Tesorería General, y que contra dicha resolución el sujeto pasivo puede presentar reclamación económico-administrativa en la forma y plazos antes referidos. 


\section{Bibliografía}

E. García de Enterría y T. Ramón Fernández: «Curso de Derecho Administrativo». Ed. Cívitas.

J. González Pérez: «Comentarios a la Ley de Procedimiento Administrativo». Ed. Cívitas.

J. González Pérez y J. Toledo Jáudenes: «Comentarios al Reglamento Económico-Administrativo». Ed. Cívitas.

A. Zabala Rodríguez-Fornos y otros: «Recaudación. Aspectos sustantivos y procedimentales. Comentarios al R.D.1.684/1990». Ed. CISS.

A. Sendín Blázquez y J. Méndez Deza: «Impugnación de los actos de gestión recaudatoria de la Seguridad Social». Revista de Relaciones Laborales. Año 1988, Volumen I.

A. Palomar Ojeda y H. Losada González: «La Jurisdicción competente para conocer de la impugnación de los actos en materia de recaudación de la Seguridad Social. Análisis de una controversia.» Revista de Seguridad Social, núm. 32 Octubre-Diciembre 1986.

S. González Ortega: «La extensión de la jurisdicción social en materia de Seguridad Social y otras afines». Revista Relaciones Laborales núm. 24, Octubre 1990.

J. Cruz Villalón: «El control judicial de los actos de la Administración Laboral. La extensión de las jurisdicciones laborales y contencioso-asministrativas». Revista Relaciones Laborales núm 18 de 1990.

V. Conde Martín de Hijas: «La jurisdicción social y la jurisdicción contenciosoadministrativa: concurrencia y conflictos». Rev. Relaciones Laborales, año 1989, Vol. I, pags. 140 y ss. 